\title{
ABSTRACTS OF MEMOIRS
}

\section{RECORDING WORK AT THE PLYMOUTH LABORATORY}

\author{
BAKER, P. F. \& SChAPIRA, A. H. V., 1980. Anaesthetics increase light emission from aequorin at \\ constant ionised calcium. Nature, London, 284, I68-169.
}

The isolation by Shimomura, Johnson and Saiga of a protein, aequorin, that emits light in the presence of micromolar concentrations of ionized calcium opened up new possibilities for the study of ionized calcium inside cells. It is a relatively simple matter to introduce aequorin into large cells by microinjection, and the rate of light emission gives a direct measure of intracellular free calcium. During an investigation into the action of certain anaesthetics on squid axons, we noticed that these agents always increase the light output from intracellular aequorin. Subsequent analysis has now revealed that this does not result from a rise in ionized calcium inside the axon but seems to reflect a direct effect of the anaesthetic agent on the aequorin molecule. The agents studied all produce greater activation of the light-emitting reaction at a constant level of ionized calcium. These rather simple observations have several important biological implications: (I) aequorin might be an interesting model system for studying interaction between anaesthetics and proteins, (2) other Ca-sensitive proteins might behave like aequorin, their affinity for calcium being subject to modulation, and (3) such modulation of endogenous Ca-binding proteins might contribute to the mechanism of anaesthesia.

Clarke, M. R. \& Trillmich, F., I980. Cephalopods in the diet of fur seals of the Galapagos Islands. fournal of Zoology, 190, 2 I I-2 I 5.

Vomir from seven Galapagos fur seals (Arctocephalus galapagoensis Heller, 1904) examined at Cabo Hammond, Fernandina Island contained 459 cephalopod beaks. Of these the 275 lower beaks were identified and measured. Onychoteuthis banksi (Leech, 1917) comprised $96.4^{\circ} \mathrm{n}$, ommastrephid species $I .8 \%$ and two other species $I \cdot I \%$. Estimates from beak lengths show that Onychoteuthis comprised $74 \%$, ommastrephids $25^{\circ}$ and other species $1 \%$ of the weight of squids represented by lower beaks.

Gillespie, J. I. \& Meves, H., I980. The time course of sodium inactivation in squid giant axons. fournal of Physiology, 299, 289-307.

The time course of $\mathrm{Na}$ inactivation was studied in intact and perfused squid giant axons under voltage-clamp conditions.

The pulse programme consisted of a conditioning pulse of varying duration, followed after an interval of 3-8 ms by a test pulse. The measurements were done in sea water with $1 / 3$ or $1 / 5$ of the normal $\mathrm{Na}$ concentration. In most experiments a $100 \mu \mathrm{s}$ conditioning pulse was sufficient to reduce $I_{\text {va peak }}$ elicited by the test pulse. In some experiments even a $50 \mu$ s conditioning pulse produced a clear reversible decrease of $I_{\mathrm{Na}}$ peak. We conclude that the upper limit for an initial delay in the development of inactivation is $50-100 \mu \mathrm{s}$; this applies to temperatures between 0 and $13 \mathrm{C}$ and membrane potentials between -40 and $15 \mathrm{mV}$. The decrease of $I_{\mathrm{Na}}$ peak with increasing duration of the conditioning pulse was consistent with an exponential decay starting at 50 or $100 \mu \mathrm{s}$.

With large $\mathrm{Na}$ currents in full $\mathrm{Na}$ sea water the time course of inactivation became sigmoid. This is attributed to a long-lasting tail of inward current which follows the conditioning pulse and produces a voltage drop across the series resistance.

If the conditioning pulse and the test pulse were not separated by an interval, $I_{\text {sa peak }}$ showed a sigmoid depen dence on the duration of the conditioning pulse. With sufficiently strong conditioning pulses $I_{\mathrm{Na}}$ peak could even increase in size.

MONTGOMERY, J. C. \& RoBerTs, B. L., I979. Organization of vestibular afferents to the vestibular nuclei of the dogfish. Brain, Behavior and Evolution, 16, $8 \mathrm{I}-98$.

Electrophysiological and light microscopical studies were made on the vestibular area of the dogfish hindbrain. Three vestibular nuclei were distinguished: the superior nucleus (VES), the 
magnocellularis nucleus (VEM), and the ventral nucleus (VEV). The distribution of field potentials evoked in the hindbrain by stimulation of nerve VIII confirms the location and extent of the vestibular nuclei. It also raises the possibility of a direct contralateral projection of vestibular nerve fibres. Unit studies confirm the interpretation of the field potentials and provide evidence of mono- and polysynaptic activation of vestibular nuclear neurons by vestibular afferents.

Pingree, R. D. \& Griffiths, D. K., 1980. Currents driven by a steady uniform wind stress on the shelf seas around the British Isles. Oceanologica acta, 3, 227-236.

A numerical model is used to derive the currents driven by a steady wind stress on the shelf seas around the British Isles. Water budgets for the North Sea and Celtic Sea are derived for varying wind directions and the dynamical significance of the derived circulations is discussed.

Pingree, R. D. \& Griffiths, D. K., I980. A numerical model of the $M_{2}$ tide in the Gulf of St Lawrence. Oceanologica acta, 3, 221-225.

A two-dimensional numerical model of the $M_{2}$ tide in the Gulf of St Lawrence and the St Lawrence Estuary is developed in spherical polar coordinates. The model is used to predict frontal regions separating areas of tidally mixed waters from areas showing pronounced summer stratification. Marked increases in biological productivity may be associated with upwelling and mixing in these regions.

WhITFIELD, M., I979. Activity coefficients in natural waters. In Activity Coefficients in Electrolyte Solutions, vol. II (ed. R. M. Pytkowicz), pp. I 53-299. Boca Raton, Florida: CRC Press.

The thermodynamics of multi-component electrolyte solutions is reviewed and pragmatic methods for calculating the activity coefficients of electrolyte and non-electrolyte components are identified. The application of these procedures is described for the calculation of activity coefficients in natural waters ranging from rain water to hypersaline brines. Particular emphasis is placed on the estimation of activity coefficients in sea water and the accuracy of the calculation procedures is assessed, where possible, by comparison with experimental data. Relevant information is collected in some ninety tables distributed throughout the text and a detailed Appendix consisting of a further 26 tables is included to provide a full numerical background to the use of the various models discussed in the test.

Whiting, H. P. \& Bone, Q., I980. Ciliary cells in the epidermis of the larval Australian dipnoan, Neoceratodus. Zoological fournal of the Linnean Society, 68, I25-137.

Newly hatched Australian lungfish, Neoceratodus forsteri Krefft, develop a ciliary current over the skin surface which continues for more than six weeks of larval life. The gill surface under the opercula also becomes ciliated. The ciliary cells producing the current are found to develop in like manner to those in several amphibian embryos and larvae. The long duration of ciliary currents in one of the most primitive living gnathostomes has ontogenetic and phylogenetic implications. 